\title{
Routine Use of Zoledronic Acid in Early-Stage Breast Cancer
}

Kathleen Harnden, MD, and Kimberly Blackwell, MD

\begin{abstract}
Zoledronic acid, a potent nitrogen-containing bisphosphonate, plays a key role in preventing complications of bone metastases in metastatic breast cancer, but its affect on early-stage breast cancer has been unclear. The preclinical data supporting the anticancer effects of zoledronic acid are compelling and several recent clinical trials have suggested that it reduces breast cancer recurrence in certain patient subgroups. Given these anticancer effects and reasonable safety profile, this therapeutic option could be discussed with patients. This article focuses on the results of supporting preclinical and clinical data evaluating the role of zoledronic acid in adjuvant breast cancer therapy. (J Natl Compr Canc Netw 2015;13:480-486)
\end{abstract}

Bisphosphonates are an integral part of treatment for bone metastases in many malignancies, including breast cancer. Bone metastases can have devastating consequences, including severe pain, fractures, hypercalcemia, and spinal cord compression, which can be prevented with bisphosphonate therapy. Unlike in metastatic disease, the role of bisphosphonates in earlystage breast cancer (ESBC) has been unclear.

Preclinically, bisphosphonates have been shown to play a role in suppressing tumor growth beyond their potent antiosteoclast effects and to have systemic anticancer activity in operable breast cancer. In particular,

From Duke Cancer Institute, Duke University Medical Center, Durham, North Carolina.

Submitted November 3, 2014; accepted for publication

February 20, 2015.

Dr. Harnden has disclosed that she has no financial interests, arrangements, affiliations, or commercial interests with the manufacturers of any products discussed in this article or their competitors. Dr. Blackwell has disclosed that she is consultant for Novartis.

Correspondence: Kimberly Blackwell, MD, Duke University Medical Center, 2301 Erwin Road, Box 3893, Durham, NC 27710.

E-mail: kimberly.blackwell@dm.duke.edu nitrogen-containing bisphosphonates, such as zoledronic acid, have shown the most promising results in adjuvant breast cancer therapy. An ongoing trial has completed accrual (S0307) comparing zoledronic acid, ibandronate, and clodronate in patients with ESBC that may further inform bisphosphonate treatment decisions. ${ }^{1}$ Currently, zoledronic acid is the most potent and well-studied bisphosphonate in ESBC. Amassing the recent clinical data from many large trials in ESBC, zoledronic acid is proving to be an important adjuvant treatment in selected patients with breast cancer. Although other bisphosphonates have been studied in vitro and in clinical trials, the data on these are less consistent. This article presents a thorough and focused review on the role of zoledronic acid in ESBC treatment.

\section{Zoledronic Acid Preclinical Anticancer Activity}

Zoledronic acid has significant anticancer effects on the invasive capabilities, growth, and replication of cancer cells. Hanahan and Weinberg ${ }^{2}$ described the original "hallmarks of cancer," characterized by the following capabilities of malignant cells: self-sufficiency in growth signals, insensitivity to antigrowth signals, ability to invade and metastasize, limitless replicative potential, sustained angiogenesis, and evasion of apoptosis. As shown in Figure 1, zoledronic acid has effects on each of these 6 critical, defining capabilities of cancer. Accumulating evidence shows that zoledronic acid affects the ability of malignant cells to successfully metastasize throughout the body, change the tumor microenvironment at the sites of metastasis, and induce malignant cell apoptosis.

\section{Anticancer Effects on Tumor Cells}

A key step in the development of metastasis is the migration of mesenchymal stem cells to the site of spread. 


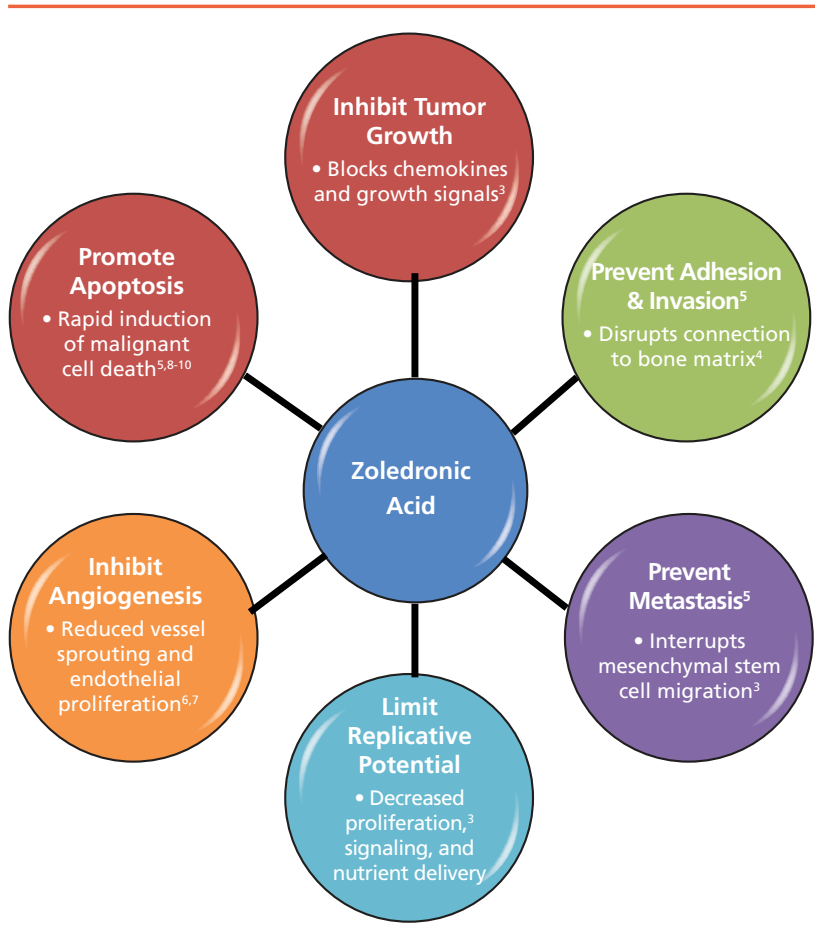

Figure 1 Anticancer activity of zoledronic acid.

Zoledronic acid blocks secretion of essential chemokines and growth factors in breast cancer cell migration and interrupts the migration of mesenchymal stem cells. ${ }^{3}$ Adhesion to the site of metastasis is another crucial step in the process of cancer spread. Van der Pluijm et $\mathrm{al}^{4}$ showed that although breast cancer cells typically adhere rapidly to the extracellular bone matrix, the administration of nitrogen-containing bisphosphonates prevents the adhesion and spread of breast cancer cells to the bone matrix in a dose-dependent fashion in vitro. This correlates with the extent of metastatic spread. Hiraga et $\mathrm{al}^{5}$ showed that zoledronic acid inhibited breast cancer cell migration and invasion in a dose-dependent manner, decreased visceral and bony metastases in a breast cancer mouse model, and prolonged overall survival compared with mice that did not receive zoledronic acid.

\section{Anticancer Effects on Angiogenesis and Apoptosis}

Zoledronic acid is also able to alter the tumor microenvironment and thereby decrease tumor growth. Zoledronic acid has potent antiangiogenic effects and inhibits both endothelial cell proliferation and blood vessel sprouting and formation. ${ }^{6,7}$ Restricting angiogenesis and thereby the delivery of key nutrients to the tumor significantly limits tumor growth and decreases the size and local impact of metastases.
Zoledronic acid has also been shown to induce cancer cell death. Hiraga et $\mathrm{al}^{5}$ demonstrated that zoledronic acid rapidly induced apoptosis in breast cancer cells in vitro. This is consistent with several other studies showing that bisphosphonates induce apoptosis of breast cancer cells. ${ }^{8,9}$ Senaratne et $\mathrm{al}^{10}$ showed that zoledronic acid was the most potent bisphosphonate to induce breast cancer cell apoptosis in several breast cancer cell lines. Preclinical data show the increasingly recognized inhibitory effects of zoledronic acid on the breast cancer cell's fundamental abilities of immortality, proliferation, invasion, and destruction.

\section{Zoledronic Acid Reduces Disseminated Tumor Cells} Disseminated tumor cells (DTCs) are an exciting area of interest in the development of therapies for ESBC. DTCs are surrogate prognostic markers associated with a higher risk of recurrence. DTCs are thought to be present early in the disease course, localize to the skeleton, and reside in a dormant state for many years before developing into incurable metastatic breast cancer. ${ }^{11}$ It is estimated that up to half of patients with ESBC have DTCs, ${ }^{12}$ and chemotherapy does not clear DTCs from the bone marrow. Preclinical data in a mouse model have shown a profound decrease in circulating tumor cells after a single dose of zoledronic acid compared with controls. ${ }^{13}$ Two small nonrandomized trials showed that zoledronic acid clears DTCs from the bone marrow. ${ }^{14,15} \mathrm{~A}$ recent phase II study evaluated the ability of zoledronic acid to reduce DTCs in patients with ESBC undergoing neoadjuvant chemotherapy ${ }^{16} ; 43 \%$ of patients in the zoledronic acid group and $48 \%$ of controls had detectable DTCs at diagnosis. After treatment with zoledronic acid, only $30 \%$ continued to have detectable DTCs versus no change $(48 \%)$ in the control group, although this was not statistically significant $(P=.054)$. Additionally, of the patients without DTCs at diagnosis, $87 \%$ of those in the zoledronic acid group remained free of DTCs at 3 months compared with only $60 \%$ in the control group. Another randomized controlled trial in patients with ESBC with detectable DTCs at diagnosis showed that all patients treated with zoledronic acid became DTC-negative at 24 months after diagnosis compared with a significant number in the control group who had persistent detectable DTCs $(P=.032) .{ }^{17}$ Although these trials are small, the results offer a promising hypothesis for zoledronic acid's anticancer activity beyond its antiosteoclast effects. 
Harnden and Blackwell

\section{Clinical Evidence for Anticancer Effects of Zoledronic Acid}

\section{Zoledronic Acid Improves Disease-Free Survival in ESBC: Published Phase III Studies}

Table 1 summarizes the completed and published phase III studies that have evaluated the anticancer effects of zoledronic acid in ESBC.

The first study, ABCSG-12, is a study that randomized 1803 premenopausal patients to zoledronic acid or no zoledronic acid in the setting of ovarian suppression and endocrine therapy. The patients who received zoledronic acid had an impressive improvement in disease-free survival (hazard ratio [HR], 0.64; P=.01) at 84 months of follow-up (Table 1)..$^{18}$ This represents a $36 \%$ reduction in the risk of disease progression compared with those who did not receive zoledronic acid. A trend was also seen toward improved overall survival that was not statistically significant, with only 30 deaths in the group receiving zoledronic acid compared with 43 deaths in the control group $(P=.09) .{ }^{19}$ The number needed to treat with zoledronic acid to prevent disease progression in 1 patient was 31 at 47.8 months of follow-up. ${ }^{18}$ The updated ABCSG-12 results at 94 months of follow-up continue to show improved disease-free survival (HR, 0.77; $P=.042$ ) and overall survival (HR, $0.66 ; P=.064$ ) with zoledronic acid therapy, although no longer significant at the predefined significance level. ${ }^{20}$

The AZURE trial is the largest and most recent prospective trial to date evaluating zoledronic acid in addition to standard adjuvant therapy in ESBC. ${ }^{21}$ At the final efficacy analysis after a median follow-up of 84 months, no significant difference was seen in disease-free or overall survival in the group that received zoledronic acid compared with the group that did not. However, zoledronic acid did significantly reduce the incidence of bone metastases at first recurrence (adjusted HR, 0.78; 0.63-0.96; P=.020) and the incidence of bone metastases at any time (HR, $0.81 ; 0.68-0.97 ; P=.022)$. Zoledronic acid markedly improved extraskeletal invasive disease-free survival events in patients who were more than 5 years since menopause at the time of trial entry (HR, $0.77 ; 0.63$ 0.96 ) but not in other menopausal groups, as seen in Table 2. A trend was seen toward improved overall survival in the postmenopausal group that did not reach statistical significance (HR, $0.81 ; 0.63-1.04$; $P=.12$ ). Zoledronic acid was protective against fractures in all women (HR, 0.69; 0.53-0.90; $P=.005$ ), including after a disease-free survival event.

The ZO-FAST trial enrolled postmenopausal women with ESBC receiving adjuvant letrozole and randomized them to early versus delayed zoledronic acid. ${ }^{22}$ Both immediate zoledronic acid and delayed zoledronic acid had benefits compared with no zoledronic acid in risk of fracture and bone mineral density, the primary outcome of the study. When breast cancer activity was retrospectively examined, the early zoledronic acid group had improved diseasefree survival by $34 \%$ (HR, $0.66 ; P=.0375)$ and both local and distant recurrences were decreased compared with delayed zoledronic acid. Delayed zoledronic acid also improved disease-free survival compared with no zoledronic acid (HR, 0.46; $P=.0334$ ). Interestingly, both local and distant recurrences were

\begin{tabular}{|c|c|c|c|c|c|c|c|}
\hline Study & $\begin{array}{l}\text { Experimental } \\
\text { Comparison }\end{array}$ & ZA Schedule & $\begin{array}{l}\text { Length } \\
\text { of ZA }\end{array}$ & $\begin{array}{l}\text { Number of } \\
\text { Patients }\end{array}$ & DFS Hazard Ratio & $\begin{array}{l}\text { OS Hazard } \\
\text { Ratio }\end{array}$ & $\begin{array}{l}\mathrm{F} / \mathrm{U} \\
\text { (mo) }\end{array}$ \\
\hline ABCSG-12 & $\begin{array}{l}\text { ZA } \\
\text { Observation }\end{array}$ & $4 \mathrm{mg} \mathrm{q} 6 \mathrm{mo}$ & $3 y$ & $\begin{array}{l}900 \\
903\end{array}$ & $\begin{array}{l}0.77(0.60-0.99) \\
P=.04\end{array}$ & $\begin{array}{l}0.66(0.43-1.02) \\
P=.06\end{array}$ & $\begin{array}{l}94 \\
94\end{array}$ \\
\hline AZURE ${ }^{21}$ & $\begin{array}{l}\text { ZA } \\
\text { Observation }\end{array}$ & $\begin{array}{l}4 \mathrm{mg} \mathrm{q} 4 \mathrm{wk} \times 6 \\
\rightarrow \mathrm{q} 3 \mathrm{mo} \times 8 \rightarrow \\
\mathrm{q} 6 \mathrm{mo} \times 5\end{array}$ & $5 y$ & $\begin{array}{l}1681 \\
1678\end{array}$ & $\begin{array}{l}0.94(0.82-1.06) \\
P=.30\end{array}$ & $\begin{array}{l}0.93(0.81-1.08) \\
P=.37\end{array}$ & $\begin{array}{l}84 \\
84\end{array}$ \\
\hline ZO-FAST ${ }^{22}$ & $\begin{array}{l}\text { Early ZA } \\
\text { Delayed ZA }\end{array}$ & $4 \mathrm{mg} \mathrm{q} 6 \mathrm{mo}$ & $5 y$ & $\begin{array}{l}532 \\
533\end{array}$ & $\begin{array}{l}0.66^{\mathrm{a}}(0.44-0.97) \\
P=.038\end{array}$ & $\begin{array}{l}0.69(0.42-1.14) \\
P=.15\end{array}$ & $\begin{array}{l}54 \\
54\end{array}$ \\
\hline Z-FAST ${ }^{23}$ & $\begin{array}{l}\text { Early ZA } \\
\text { Delayed ZA }\end{array}$ & $4 \mathrm{mg} \mathrm{q} 6 \mathrm{mo}$ & $5 \mathrm{y}$ & $\begin{array}{l}301 \\
301\end{array}$ & $\begin{array}{l}9.8 \% \text { vs } 10.5 \% \\
P=.63\end{array}$ & $\begin{array}{l}2.3 \% \text { vs } 1.3 \% \\
P=.63\end{array}$ & $\begin{array}{l}61 \\
61\end{array}$ \\
\hline
\end{tabular}

Abbreviations: DFS, disease-free survival; F/U, follow-up; OS, overall survival; ZA, zoledronic acid. ${ }^{a} P<.05$. 
Zoledronic Acid Adjuvant Therapy

Table 2 Zoledronic Acid in Postmenopausal Early-Stage Breast Cancer

\begin{tabular}{|c|c|c|c|c|c|c|}
\hline Study & $\begin{array}{l}\text { Number of } \\
\text { Postmenopausal } \\
\text { Patients }\end{array}$ & $\begin{array}{l}\text { Number of Non- } \\
\text { postmenopausal } \\
\text { Patients }\end{array}$ & $\begin{array}{l}\text { DFS } \\
\text { Postmenopausal }\end{array}$ & $\begin{array}{l}\text { DFS Nonpost } \\
\text { menopausal }\end{array}$ & $\begin{array}{l}\text { OS } \\
\text { Postmenopausal }\end{array}$ & $\begin{array}{l}\text { OS Non- } \\
\text { postmenopausal }\end{array}$ \\
\hline ABCSG-12 19 & $\begin{array}{l}1803 \text { (ovarian } \\
\text { suppression) }\end{array}$ & 0 & $\begin{array}{l}0.64^{\mathrm{a}}(0.46-0.91) \\
P=.01\end{array}$ & $\mathrm{~N} / \mathrm{A}$ & $\begin{array}{l}0.60(0.32-1.11) \\
P=.10\end{array}$ & N/A \\
\hline AZURE ${ }^{21}$ & 1041 & 2318 & $\begin{array}{l}0.77^{\mathrm{a}}(0.63-0.96) \\
P<.05\end{array}$ & $\begin{array}{l}1.03 \\
(0.89-1.20)\end{array}$ & $\begin{array}{l}0.81(0.63-1.04) \\
P>.05\end{array}$ & $1.04(0.86-1.25)$ \\
\hline Z-FAST ${ }^{23}$ & 602 & 0 & $\begin{array}{l}9.8 \% \text { vs } 10.5 \% \\
P=.63\end{array}$ & N/A & $\begin{array}{l}2.3 \% \text { vs } 1.3 \% \\
P=.63\end{array}$ & N/A \\
\hline
\end{tabular}

Abbreviations: DFS, disease-free survival; N/A, not applicable; OS, overall survival. ${ }^{\text {a }} P<.05$.

reduced in patients who received immediate versus delayed zoledronic acid (local recurrences, $0.9 \%$ vs $2.3 \%$; distant recurrences, $5.5 \%$ vs $7.7 \%$ ). A trend was seen toward improved overall survival in the immediate zoledronic acid group at a median follow-up of 61.6 months, but it was not statistically significant (95.2\% vs $93.9 \%)$.

In the Z-FAST trial, 602 postmenopausal women with ESBC receiving adjuvant letrozole were randomized to upfront or delayed zoledronic acid at 4 mg every 6 months for 5 years. ${ }^{23}$ Although the primary end point was bone mineral density, time to disease recurrence was a secondary end point. At the 12-, 24-, 36-, and 48-month analyses, the rates of disease recurrence were improved with the upfront zoledronic acid group, and by the final analysis at 61 months, a trend favored upfront zoledronic acid, which was not statistically significant. Disease recurrence occurred in 5.3\% of patients receiving early zoledronic acid versus $7.0 \%$ of patients receiving delayed zoledronic acid $(P=.628)$.

The phase III Neoadjuvant Trial Add-On (NATAN) study presented at the 2013 San Antonio Breast Cancer Symposium (SABCS) showed a trend for benefit of zoledronic acid in postmenopausal women. ${ }^{24}$ Nearly 700 women with operable breast cancer and residual tumor after 2 cycles of anthracycline and taxane neoadjuvant chemotherapy were enrolled and randomized to zoledronic acid for 5 years versus observation. A preplanned interim analysis at 48 months did not show a significant difference in disease-free survival $(P=.7885)$ or overall survival $(P=.4082)$. However, only $50 \%$ of the required events have occurred, and it is estimated that it will be 6 to 8 more years before the final analysis. ${ }^{25}$ Similarly, the smallest companion study to the Z-FAST and ZO-FAST trials, EZO-FAST, was presented at the ASCO meeting. In this trial, 500 postmenopausal women on adjuvant letrozole for ESBC were randomized to early versus delayed zoledronic acid for 5 years. The preplanned interim analysis at 36 months did not show a disease-free survival benefit in the early zoledronic acid treatment group. However, only 29 events were seen at the interim analysis, precluding a robust disease-free survival analysis.

\section{Safety of Zoledronic Acid Across the Clinical Trials}

Zoledronic acid is generally well tolerated with few serious adverse events (SAEs; Table 3). Mild to moderate events that occur with zoledronic acid administration include arthralgias, fatigue, and hypocalcemia. The hypocalcemia is effectively mitigated with calcium and vitamin $\mathrm{D}$ supplementation. In these studies, SAEs were similar in the group receiving zoledronic acid and the group receiving standard treatment alone. Arthralgia was the only symptom in both ABCSG-12 and AZURE that was significantly more common in the zoledronic acid treatment group than in the control group. The most feared complication of zoledronic acid treatment is osteonecrosis of the jaw $(\mathrm{ONJ})$, which was rare in these clinical trials. ABCSG- 12 reported 0 cases of ONJ of 1803 patients, 900 of whom received the bisphosphonate. AZURE reported a $1.54 \%$ incidence (26 of 1685 cases in the bisphosphonate arm) of ONJ. ${ }^{26}$ Z-FAST reported 0 cases among the 602 patients on trial and ZO-FAST reported 3 cases among 1065 patients $(0.56 \%)$, all in the upfront zoledronic acid group. Overall, significant safety events were rare with adjuvant zoledronic acid therapy, and the incidence of $\mathrm{ONJ}$ was low. 
Harnden and Blackwell

\begin{tabular}{|c|c|c|c|c|c|c|}
\hline Trial & ONJ & Bone Pain & Fatigue & Headache & Arthralgia & Fever \\
\hline ABCSG-18 ${ }^{18, a}$ & $\begin{array}{l}0 \% \\
(0 \%)\end{array}$ & $38 \%^{\mathrm{b}}(28 \%)$ & $\begin{array}{l}21 \% \\
(18 \%)\end{array}$ & $\begin{array}{l}16 \% \\
(14 \%)\end{array}$ & $\begin{array}{l}16 \%^{\mathrm{b}} \\
(14 \%)\end{array}$ & $\begin{array}{l}9 \%^{\mathrm{b}} \\
(3 \%)\end{array}$ \\
\hline AZURE $21, a$ & $\begin{array}{l}1.54 \% \\
(0 \%)\end{array}$ & NR & $\begin{array}{l}60 \% \\
(60 \%)\end{array}$ & $\begin{array}{l}10 \% \\
(9 \%)\end{array}$ & $\begin{array}{l}28 \%^{\mathrm{b}} \\
(23 \%)\end{array}$ & $\begin{array}{l}2 \% \\
(1.4 \%)\end{array}$ \\
\hline $\begin{array}{l}\text { Z-FAST }{ }^{23} \\
\text { (Upfront vs } \\
\text { delayed) }\end{array}$ & $0 \%$ & $\begin{array}{l}16 \% \\
8 \%\end{array}$ & $\begin{array}{l}33 \% \\
29 \%\end{array}$ & $\begin{array}{l}13 \% \\
12 \%\end{array}$ & $\begin{array}{l}47 \% \\
45 \%\end{array}$ & NR \\
\hline $\begin{array}{l}\text { ZO-FAST22 } \\
\text { (Upfront vs } \\
\text { delayed) }\end{array}$ & $\begin{array}{l}0.56 \% \\
0 \%\end{array}$ & $\begin{array}{l}18 \% \\
12 \%\end{array}$ & $\begin{array}{l}17 \% \\
17 \%\end{array}$ & $\begin{array}{l}14 \% \\
12 \%\end{array}$ & $\begin{array}{l}49 \% \\
46 \%\end{array}$ & $\begin{array}{l}15.2 \% \\
3.6 \%\end{array}$ \\
\hline
\end{tabular}

Abbreviations: NR, not reported; ONJ, osteonecrosis of the jaw.

${ }^{a}$ Control arm incidence indicated by parenthesis.

bSignificant difference noted between treatment and control group, $P<.05$.

\section{Possible Explanations for Different Results Across the Adjuvant Zoledronic Acid Trials}

\section{Different Patient Populations}

Although Z-FAST and ZO-FAST only enrolled postmenopausal patients, patients in ABCSG-12 were premenopausal at enrollment but in an induced lowestrogen postmenopausal hormonal state with ovarian suppression and adjuvant endocrine therapy. AZURE included premenopausal, perimenopausal, and postmenopausal women and had preplanned subgroup analyses based on menopausal group at trial entry. Emerging data in a mouse model show that in a postmenopausal bone environment, tumor growth is driven by osteoclast-mediated mechanisms, which may explain the mechanism by which postmenopausal women gain the most benefit from bisphosphonate therapy. ${ }^{27}$

There was also variability in median age of the patients included in the trials. In ABCSG-12, the median age was 44 years and in AZURE it was 51 years. In Z-FAST, the median age was 60 years with a range of 35 to 89 years, whereas with ZO-FAST the median age was 57 years, with a range of 36 to 87 years. When postmenopausal patients are compared across the trials, the benefit of zoledronic acid in reducing recurrence is more consistent.

In the AZURE trial, the benefit of postmenopausal status on zoledronic acid treatment effects was driven by significant differences in extraskeletal invasive disease-free survival events. ${ }^{21}$ In the more than 1000 women at least 5 years beyond menopause at study entry, a marked reduction in extraskeletal recurrence was seen with zoledronic acid (HR,
0.77; CI, 0.63-0.96) compared with a trend to possible increased risk in premenopausal women. In the postmenopausal group, evidence also showed that zoledronic acid treatment decreased distant diseasefree survival events (HR, 0.75; CI, 0.58-0.97) and a trend was seen toward improved overall survival (HR, 0.81; CI, 0.63-1.04). Age was explored as an alternative treatment modifier. However, in patients aged 40 to 59 years, outcomes were related to menopausal status rather than age. The effect of zoledronic acid treatment in patients in a postmenopausal state was similar across estrogen receptor-negative and estrogen receptor-positive tumors.

\section{Different Zoledronic Acid Dosing Schedules and Length of Follow-Up}

The phase III clinical trials evaluating zoledronic acid in ESBC also had differences in dosing schedules and length of follow-up, which may contribute to the heterogeneity of the results. The AZURE trial had a dose de-escalation zoledronic acid schedule, with monthly 4-mg doses broadened to every 3 months and then every 6 months during the 5 years of treatment. This is the largest prospective trial evaluating zoledronic acid with the most aggressive dosing regimen of the trials. ABCSG-12 randomized patients to $4 \mathrm{mg}$ of zoledronic acid every 6 months for 3 years of treatment. ZOFAST and Z-FAST were much smaller trials and had patients on early or delayed treatment with $4 \mathrm{mg}$ of zoledronic acid every 6 months for a total of 5 years of treatment. A comparison of dosing regimens and longer follow-up is needed to evaluate the optimal dose and length of treatment to maximize potential therapeutic effects of zoledronic acid on ESBC. 


\section{Different Concurrent Treatment Regimens}

Finally, patients in the ABCSG-12 trial did not receive chemotherapy, whereas almost all patients received chemotherapy (95\%) with or without endocrine therapy in the AZURE study. Approximately half of the patients in the Z-FAST study $(46 \%)$ and ZO-FAST study (52\%) received chemotherapy. In both Z-FAST and ZO-FAST, patients were concurrently treated with letrozole. In ABCSG-12, patients were treated with ovarian suppression and either anastrozole or tamoxifen. The AZURE patients were on a variety of standard adjuvant therapies, which included endocrine therapy alone, chemotherapy alone, endocrine treatment, and chemotherapy and trastuzumab, as indicated. It is possible that a particular adjuvant therapy combination with zoledronic acid would be most beneficial to improve disease-free survival and overall survival in these patients.

\section{Meta-Analysis Results}

Altogether, differences in overall survival were difficult to detect from each of the phase III studies, partly because of the wide range in ages in the trials, low breast cancer recurrence rate, relatively young age, and low number of deaths. Therefore, a recent large meta-analysis is helpful in understanding the clinical utility of zoledronic acid in the ESBC setting. As shown in Figure 2, Dr. Robert Coleman presented a compelling meta-analysis at SABCS 2013 evaluating zoledronic acid trials and breast cancer specific outcomes, including time to recurrence, time to distant recurrence, and mortality. ${ }^{28}$ The results in postmenopausal patients were the most striking. Adjuvant bisphosphonates significantly reduced the risk of bone recurrence by $34 \%(P=.00001)$ and significantly reduced the risk of breast cancer death by $17 \%(P=.004)$ in postmenopausal women. Premenopausal women did not seem to have breast cancer-specific benefits from bisphosphonates. On preplanned subgroup analyses, he found that the risk reductions were similar irrespective of nodal status, estrogen receptor status, and whether the patient received chemotherapy. A total of $65 \%$ of the patients received zoledronic acid and the other $35 \%$ received either ibandronate $(24 \%)$, pamidronate $(8 \%)$, rise-
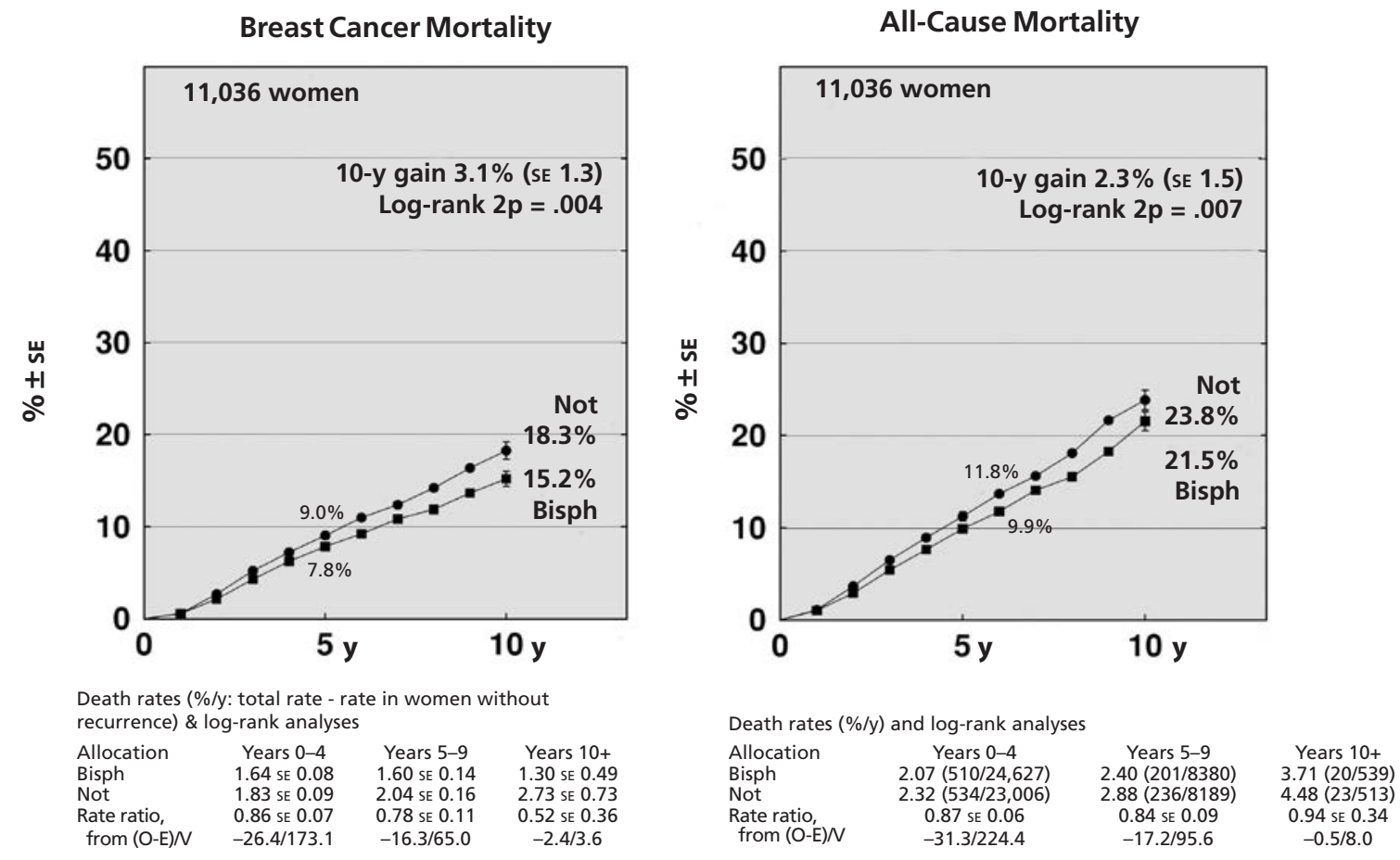

Figure 2 Breast cancer mortality in postmenopausal women.

Abbreviations: Bisph, bisphosphonates; $\mathrm{E}$, expected; O, observed; V, variance.

Adapted from Coleman R, Gnant M, Paterson A, et al. Effects of bisphosphonate treatment on recurrence and cause-specific mortality in women with early breast cancer: a meta-analysis of individual patient data from randomised trials [abstract]. Presented at 2013 San Antonio Breast Cancer Symposium; December 12, 2013; San Antonio, Texas. Abstract S4-07; with permission. 
Harnden and Blackwell

dronate $(2 \%)$, or alendronate $(1 \%)$. This metaanalysis provides additional strength to the benefits of zoledronic acid in postmenopausal women with ESBC.

\section{Conclusions}

Based on randomized studies and a recent meta-analysis presented at SABCS, zoledronic acid may have a role in reducing recurrence and improving breast cancer mortality in patients with ESBC. This impact seems to have the most potential in postmenopausal women or in those with an induced low estrogen state through ovarian suppression. Zoledronic acid is considered safe and has numerous secondary benefits, including improving bone mineral density on adjuvant endocrine therapy and reducing fractures, even when only given 2 times a year. This is a reasonable approach to discuss with patients, especially those who are facing postmenopausal breast cancer or who would have been eligible for ABCSG-12.

\section{References}

1. S0307. Phase III trial of bisphosphonates as adjuvant therapy for primary breast cancer. Clin Adv Hematol Oncol 2005;3:852-854.

2. Hanahan D, Weinberg RA. The hallmarks of cancer. Cell 2000;100:57-70.

3. Gallo M, De Luca A, Lamura L, Normanno N. Zoledronic acid blocks the interaction between mesenchymal stem cells and breast cancer cells: implications for adjuvant therapy of breast cancer. Ann Oncol 2012;23:597-604.

4. van der Pluijm G, Vloedgraven $H$, van Beek E, et al. Bisphosphonates inhibit the adhesion of breast cancer cells to bone matrices in vitro. J Clin Invest 1996;98:698-705.

5. Hiraga T, Williams PJ, Ueda A, et al. Zoledronic acid inhibits visceral metastases in the 4T1/luc mouse breast cancer model. Clin Cancer Res 2004;10:4559-4567.

6. Stresing V, Fournier PG, Bellahcene A, et al. Nitrogen-containing bisphosphonates can inhibit angiogenesis in vivo without the involvement of farnesyl pyrophosphate synthase. Bone 2011;48:259-266.

7. Fournier P, Boissier S, Filleur S, et al. Bisphosphonates inhibit angiogenesis in vitro and testosterone-stimulated vascular regrowth in the ventral prostate in castrated rats. Cancer Res 2002;62:6538-6544.

8. Jagdev SP, Coleman RE, Shipman CM, et al. The bisphosphonate, zoledronic acid, induces apoptosis of breast cancer cells: evidence for synergy with paclitaxel. Br J Cancer 2001;84:1126-1134.

9. Fromigue O, Lagneaux L, Body JJ. Bisphosphonates induce breast cancer cell death in vitro. J Bone Miner Res 2000;15:2211-2221.

10. Senaratne SG, Pirianov G, Mansi JL, et al. Bisphosphonates induce apoptosis in human breast cancer cell lines. Br J Cancer 2000;82:14591468.

11. Riethmuller G, Klein CA. Early cancer cell dissemination and late metastatic relapse: clinical reflections and biological approaches to the dormancy problem in patients. Semin Cancer Biol 2001;11:307-311.

12. Gilje B, Nordgard O, Tjensvoll K, et al. Comparison of molecular and immunocytochemical methods for detection of disseminated tumor cells in bone marrow from early breast cancer patients. BMC Cancer 2014;14:514.
13. Haider MT, Holen I, Dear TN, et al. Modifying the osteoblastic niche with zoledronic acid in vivo-potential implications for breast cancer bone metastasis. Bone 2014;66:240-250

14. Rack B, Schindlbeck C, Strobl B, et al. [Efficacy of zoledronate in treating persisting isolated tumor cells in bone marrow in patients with breast cancer. A phase II pilot study]. Dtsch Med Wochenschr 2008;133:285-289.

15. Lin A, Park J, Melisko M, et al. Zoledronic acid as adjuvant therapy for women with early stage breast cancer and occult tumour cells in bone marrow [abstract]. Cancer Res 2007;68:Abstract 510.

16. Aft $R$, Naughton $M$, Trinkaus $K$, et al. Effect of zoledronic acid on disseminated tumour cells in women with locally advanced breast cancer: an open label, randomised, phase 2 trial. Lancet Oncol 2010;11:421-428.

17. Banys M, Solomayer EF, Gebauer G, et al. Influence of zoledronic acid on disseminated tumor cells in bone marrow and survival: results of a prospective clinical trial. BMC Cancer 2013;13:480.

18. Gnant M, Mlineritsch B, Schippinger W, et al. Endocrine therapy plus zoledronic acid in premenopausal breast cancer. N Engl J Med 2009;360:679-691.

19. Gnant M, Mlineritsch B, Stoeger H, et al. Adjuvant endocrine therapy plus zoledronic acid in premenopausal women with early-stage breast cancer: 62-month follow-up from the ABCSG-12 randomised trial. Lancet Oncol 2011;12:631-641.

20. Gnant M, Mlineritsch B, Stoeger H, et al. Zoledronic acid combined with adjuvant endocrine therapy of tamoxifen versus anastrozol plus ovarian function suppression in premenopausal early breast cancer: final analysis of the Austrian Breast and Colorectal Cancer Study Group trial 12. Ann Oncol 2015;26:313-320.

21. Coleman R, Cameron D, Dodwell D, et al. Adjuvant zoledronic acid in patients with early breast cancer: final efficacy analysis of the AZURE (BIG 01/04) randomised open-label phase 3 trial. Lancet Oncol 2014;15:9971006.

22. Coleman R, de Boer R, Eidtmann H, et al. Zoledronic acid (zoledronate) for postmenopausal women with early breast cancer receiving adjuvant letrozole (ZO-FAST study): final 60-month results. Ann Oncol 2013;24:398-405.

23. Brufsky AM, Harker WG, Beck JT, et al. Final 5-year results of Z-FAST trial: adjuvant zoledronic acid maintains bone mass in postmenopausal breast cancer patients receiving letrozole. Cancer 2012;118:1192-1201.

24. von Minckwitz G, Rezai M, Eidtmann H, et al. Postneoadjuvant treatment with zoledronate in patients with tumor residuals after anthracyclinestaxane-based chemotherapy for primary breast cancer: the phase III NATAN study (GBG 36/ABCSG XX). Presented at the 2013 San Antonio Breast Cancer Symposium; December 13, 2013; San Antonio, Texas.

25. Llombart A, Frassoldati A, Paija O, et al. Zoledronic acid prevents aromatase inhibitor-associated bone loss in postmenopausal women with early breast cancer receiving adjuvant letrozole: E-ZO-FAST 36-month follow-up. Presented at the ASCO 2009 Breast Cancer Symposium; October 8-10, 2009; San Francisco, California.

26. Coleman R, Woodward E, Brown J, et al. Safety of zoledronic acid and incidence of osteonecrosis of the jaw (ONJ) during adjuvant therapy in a randomised phase III trial (AZURE: BIG 01-04) for women with stage II/ III breast cancer. Breast Cancer Res Treat 2011;127:429-438.

27. Ottewell PD, Wang N, Brown HK, et al. Zoledronic acid has differential antitumor activity in the pre-and postmenopausal bone microenvironment in vivo. Clin Cancer Res 2014;20:2922-2932.

28. Coleman R, Gnant M, Paterson A, et al. Effects of bisphosphonate treatment on recurrence and cause-specific mortality in women with early breast cancer: a meta-analysis of individual patient data from randomised trials [abstract]. Presented at 2013 San Antonio Breast Cancer Symposium; December 12, 2013; San Antonio, Texas. Abstract S4-07. 